REVISTA DE ESTUDOS EM ARTES CÊNICAS

E-ISSN 2358.6958

\title{
Entre o acaso e a escolha: Reflexões acerca da prática do Viewpoints
}

\author{
Guilherme Meletti Yazbek
}

\section{Para citar este artigo:}

YAZBEK, Guilherme Meletti. Entre o acaso e a escolha: Reflexões acerca da prática do Viewpoints. Urdimento Revista de Estudos em Artes Cênicas, Florianópolis, v. 3, n. 42, dez. 2021.

doi DOI: http:/dx.doi.org/10.5965/1414573103422021e0103

Este artigo passou pelo Plagiarism Detection Software | iThenticate 


\title{
Entre o acaso e a escolha: reflexões acerca da prática do Viewpoints ${ }^{1}$
}

\author{
Guilherme Meletti Yazbek²
}

\begin{abstract}
Resumo
O presente artigo, de caráter reflexivo e testemunhal, teve como objetivo o cruzamento de inquietações pessoais do autor - decorrentes de sua experiência enquanto condutor da prática do Viewpoints no contexto do Núcleo Experimental de Artes Cênicas do Sesi, em São Paulo - com questões estéticas manifestadas nas décadas de 1960 e 1970, principalmente em Nova lorque, bem como com questões conceituais, filosóficas e de ordem prática presentes em 0 Livro dos Viewpoints: um guia prático para viewpoints e composição, de Anne Bogart e Tina Landau, e Standing in Space: The Six Viewpoints Theory \& Practice, de Mary Overlie. $\mathrm{Na}$ tessitura das reflexões, atravessaram também pensamentos de autores como Miriam Rinaldi, John Cage e Sally Banes, entre outros.
\end{abstract}

Palavras-chave: Anne Bogart. Formação do ator. Improvisação. Mary Overlie. Pedagogia do teatro.

\section{Between chance and choice: reflections on the practice of Viewpoints}

\begin{abstract}
This reflective and testimonial article aims to combine the author's personal concerns and his academic research. The former arises primarily from his experience as facilitor of the Viewpoints practice at the Núcleo Experimental de Artes Cênicas do Sesi (Sesi Center for Performing Arts' Experimental Nucleus) in São Paulo. The latter considers aesthetic issues from the 1960s and 1970s primarily in New York, as well as conceptual, philosophical, and practical issues in The Viewpoints Book: $A$ Practical Guide to Viewpoints and Composition, by Anne Bogart and Tina Landau, and Standing in Space: The Six Viewpoints Theory \& Practice, by Mary Overlie. In weaving together these reflections, the study leads us across the thoughts of authors such as Miriam Rinaldi, John Cage, and Sally Banes, among others.
\end{abstract}

Keywords: Actor's training. Anne Bogart. Improvisation. Mary Overlie. Theater's pedagogy.

${ }^{1}$ Revisão ortográfica e gramatical do artigo realizada por Clarisse Lyra. Poeta e tradutora com mestrado no Programa de Pós-Graduação em Língua Espanhola e Literaturas Espanhola e Hispano-Americana da FFLCHUSP. clarisse lyra@hotmail.com

${ }^{2}$ Mestrando do Programa de Pós-Graduação em Artes Cênicas da ECA-USP, sob a orientação do Prof. Dr. Luiz Fernando Ramos. Formado em Direção Teatral pela mesma universidade, é ator, diretor e professor do Núcleo Experimental de Artes Cênicas do Sesi-SP. guiyazbek@gmail.com

(9) http://lattes.cnpq.br/2287432228184612 (iD https://orcid.org/0000-0002-4377-7544 


\section{Entre el azar y la elección: reflexiones sobre la práctica de Viewpoints}

\section{Resumen}

El presente artículo, de carácter reflexivo y testimonial, tuvo como objetivo cruzar las inquietudes personales del autor - surgidas de su experiencia como conductor de la práctica de Viewpoints en el contexto del Centro Experimental de Artes Escénicas del Sesi, en São Paulo - con las problemáticas estéticas presentes en las décadas de 1960 y 1970, principalmente en Nueva York, así como con cuestiones conceptuales, filosóficas y prácticas en The Viewpoints Book: A Practical Guide to Viewpoints and Composition, de Anne Bogart y Tina Landau, y Standing in Space: The Six Viewpoints Theory \& Practice, de Mary Overlie. En la tejeduría de las reflexiones también se cruzaron pensamientos de autores como Miriam Rinaldi, John Cage y Sally Banes, entre otros.

Palabras clave: Anne Bogart. Formación actoral. Improvisación. Mary Overlie. Pedagogía del teatro. 
O Viewpoints aborda a dança e o teatro como entidades físicas semelhantes a paisagens naturais que podem ser adentradas e atravessadas. [...] O Viewpoints é dedicado à leitura do palco como uma

força da natureza.

(Overlie, 2016, p. VII)

O objetivo deste artigo, de caráter reflexivo e testemunhal, é cruzar inquietações pessoais referentes ao Viewpoints com questões estéticas manifestadas nas décadas de 1960 e 1970, principalmente em Nova Iorque, bem como com questões conceituais, filosóficas e de ordem prática presentes nos livros O Livro dos Viewpoints: um guia prático para viewpoints e composição, de Anne Bogart e Tina Landau - publicado em inglês em 2005 e em português em 2017 - , e Standing in Space: The Six Viewpoints Theory \& Practice, de Mary Overlie - publicado em 2016 e ainda sem tradução para o português.

As reflexões aqui reunidas são majoritariamente advindas de nossa experiência pedagógica na condução da prática do Viewpoints no contexto do Núcleo Experimental de Artes Cênicas do Sesi, em São Paulo - um curso livre anual de aprimoramento para jovens atores e atrizes com prévia formação técnica ou universitária, entre 18 e 27 anos. Neste contexto, vimos conduzindo a prática desde 2018, em parceria com Murillo Basso e sob a coordenação pedagógica de Miriam Rinaldi. Ao longo dos dez meses de curso, a turma vivencia um treinamento contínuo em Viewpoints, dentre outras práticas artístico-pedagógicas.

Para este exercício reflexivo, revisitamos nossos cadernos de anotações de distintos momentos de vivência com o Viewpoints, tanto na condução quanto como ator em treinamento, neste caso, com foco no curso intensivo de verão da SITI Company, com Will Bond e Gian-Murray Gianino, em 2019².

${ }^{3}$ The Viewpoints approach both dance and theater as physical entities akin to natural landscapes that can be entered and traversed. [...]. The Viewpoints is dedicated to reading the stage as a force of nature. Esta e todas as traduções do inglês para o português são de nossa autoria.

\footnotetext{
${ }^{4}$ Tal experiência foi vivida pelo autor deste artigo, exclusivamente. O curso foi conduzido por Bond e Gianino, atores do Saratoga International Theater Institute ou, simplesmente, SITI Company, companhia teatral fundada em 1992 por Anne Bogart e Tadashi Suzuki. Tradicionalmente, os treinamentos da companhia sejam eles internos ou abertos ao público - têm duração diária de três horas e são conduzidos por dois atores ou atrizes da companhia de maneira intercalada, um(a) à frente da primeira metade, com treinamento da técnica Suzuki, e outro(a) à frente da segunda metade, com o Viewpoints.
} 
Dito isto, apresentamos a seguir as reflexões em seis partes.

\section{O mais simples é o mais complexo}

No capítulo d'O Livro dos Viewpoints intitulado "Como começar?", Bogart e Landau (2017) listam os requisitos físicos (espaciais) para se praticar o Viewpoints e, em seguida, explicam alguns preceitos e exercícios introdutórios anteriores à prática, mais especificamente, com os nove viewpoints ${ }^{5}$. Em outras palavras, tratase dos "conceitos básicos por trás dos Viewpoints" (Bogart e Landau, 2017, p. 40). Como ocorre no decorrer de todo o livro, as questões conceituais e filosóficas da prática estão diluídas nas explicações dos exercícios, contando apenas com algumas poucas partes argumentativas. Neste "guia prático", a teoria é muitas vezes exposta nas propostas de vivências e mais bem compreendida em ação.

No capítulo em questão, as autoras fazem uso da frase "Se você não puder dizer, aponte", de Wittgenstein, esclarecendo justamente que as práticas apontam melhor para os pré-requisitos do Viewpoints do que a exposição destes. Consequentemente, é possível compreender que os preceitos para se iniciar o treinamento em Viewpoints são especialmente difíceis de se explicar. Aquilo que antecede a prática com os nove viewpoints, efetivamente - ou seja, aquilo que é mais básico, o que é mais "simples" - , é quiçá o mais difícil de se explicar e talvez o mais importante de se praticar. Paradoxalmente, o mais simples é o mais complexo.

Lançaremos luz neste momento aos princípios da visão periférica, do soft focus, da escuta extraordinária e da atentividade ${ }^{6}$. Aventamos a hipótese de que esses princípios se referem praticamente a uma mesma questão, vista de ângulos distintos. Pedagogicamente falando, os quatro termos apontam para um mesmo objetivo: a presença cênica. Quando na condução da prática do Viewpoints,

\footnotetext{
${ }^{5}$ As reflexões neste artigo têm como foco a relação dos corpos em jogo entre si e com o espaço, por isso os nove viewpoints físicos citados. Não estão no escopo das reflexões aqui reunidas os viewpoints vocais, ainda que estes também estejam presentes em nossa prática pedagógica. 
percebemos que evocar uma ou outra expressão durante os exercícios se liga diretamente à percepção, por parte do condutor, do caminho de cada performer em treinamento. Trata-se de uma questão didática, portanto. Em determinada situação, é de maior valia para o performer que a condução evoque uma ou outra imagem específica - "Ative a visão periférica", "Trabalhe com soft focus", "Escute com todo o corpo", “Atente-se para o que já está acontecendo” - , mas o objetivo é praticamente o mesmo.

Visão periférica, como a própria expressão já explana, diz respeito à ação de ativar as bordas do campo de visão, desierarquizando-o e se atentando para toda a informação que chega através do olhar, não se restringindo ao centro da visão ou àquilo que está imediatamente à frente do observador. Entretanto, no exercício do livro denominado "Visão Periférica", as autoras indicam a importância de todos estarem com soft focus durante a prática. Tal olhar suave e relaxado (em tradução livre) diz respeito à não fixação em um único ponto, permitindo que as múltiplas informações do espaço e das pessoas em jogo cheguem sem que se precise buscá-las avidamente.

Em si, a expressão soft focus é quase contraditória ao unir o adjetivo suave ou macio - que, na situação, evoca relaxamento, mas também amplitude - ao substantivo foco, centro de atenção, recorte, estreitamento da visão. Resumidamente, soft focus seria um "recorte amplo"; um oxímoro, pois. Tal princípio pode ser entendido como um olhar mais receptivo do que ativo, como explicam as autoras - uma definição que costuma ser mais clara e proveitosa para os praticantes.

Com estes dois conceitos, fecha-se um pequeno circuito no qual, para ativar a visão periférica, é necessário estar com soft focus. Já o objetivo do soft focus é a relação com o ambiente através de uma visão não hierarquizada - ou hierarquizante - , o que, novamente, caracteriza a visão periférica. Resumindo, tratar-se-ia de praticar um para alcançar o outro, e vice-versa. Ambos os conceitos seriam, portanto, se não coincidentes, muito próximos.

No entanto, o circuito que sugerimos não se limitaria a estes dois termos. Ainda no exercício supracitado, há uma indicação para que os participantes 
fechem os olhos e percebam que o corpo recebe informações por meio de outros sentidos que não a visão. Ora, essa ativação de todo o sistema perceptivo para recepção e leitura do mundo à nossa volta é precisamente a explicação do conceito de escuta extraordinária. Não se limitando apenas à ação de ouvir, tratase de "escutar com o corpo inteiro, com todo o nosso ser", "escutar com o corpo inteiro sem a ideia de um resultado", com disponibilidade para o desconhecido. Ademais, quando explicam o conceito de soft focus, Bogart e Landau também o aproximam da escuta extraordinária ao afirmar que "[a]o retirar a pressão que recai sobre os olhos por serem eles os coletores dominantes e primários de informação, o corpo inteiro começa a ouvir e a coletar informação de novas e mais sensíveis formas" (Bogart e Landau, 2017, p.50-52).

Por fim, estaria incluída neste circuito de preceitos para a prática do Viewpoints a contínua atentividade aos outros, no tempo e no espaço, o que seria o resultado dos três conceitos já explicados. Em suma, trata-se de ativar a visão periférica através de soft focus para, com uma escuta extraordinária, estar continuamente atento a todo o espaço circundante e, portanto, presente espacial e temporalmente. No Viewpoints, pratica-se o estar em jogo, em relação, sempre, o que propicia um caminho de apaziguamento do ego - da ideia de genialidade - e das vontades cristalizadas, em favor de uma conexão fina e sensível com os parceiros com quem se compartilha um espaço.

Além disso, sendo o espaço que nos circunda também ocupado por outros corpos, este configura-se como um espaço sempre cambiante. Por isso, as quatro habilidades comentadas são contínuas e inesgotáveis, e por isso dizemos que o mais simples é o mais complexo: é por elas que começamos, mas é também a elas que sempre retornamos.

\section{"Mas, eu posso olhar para o lado?"}

Tal pergunta - que costumeiramente ouvimos em turmas que estão iniciando seu treinamento em Viewpoints - decorre majoritariamente de uma ideia preconcebida sobre a técnica. Há um juízo que paira no ar de que o Viewpoints é algo frio e de que os performers beiram o automatismo ao praticá- 
lo, sem poder sequer olhar para o lado; uma inverdade, já dizemos de saída. Contudo, interessa-nos buscar entender de onde possivelmente advém este pensamento.

Sobre a ação do olhar, esclarecemos desde já: esta é livre. O soft focus e a visão periférica visam justamente a um olhar liberto, mais amplo, que consiga receber uma gama de informações de todo o espaço circundante - e não uma única informação fixada (e, portanto, hierarquizada) no centro do campo de visão.

Entretanto, olhar repetidamente para o lado a fim de "conferir" se se está fazendo algo "certo" - ou, digamos, no momento preciso - não é uma atitude produtiva para o treinamento e está inclusive citada na bem-humorada lista de "maus hábitos" que Bogart e Landau apresentam. Há, no entanto, uma numerosa gama de dinâmicas espaciais distintas na prática do Viewpoints.

De um lado, alguns treinamentos iniciais de uníssono ou também as raias, por exemplo, são práticas bastante rigorosas na frontalidade e na ativação de todo o aparelho sensório. Nestes casos, portanto, trata-se sim de um exercício (e de um desafio!) manter o olhar à frente para buscar a ativação da visão periférica e da escuta extraordinária. Ainda assim, há de se ter um cuidado para não enrijecer demais o olhar, não se transformar em um autômato - figura que parece assombrar o Viewpoints.

De outro lado, em práticas como o fluxo, o trabalho na grade (grid) ou o open Viewpoints, apenas para citar algumas, a relação é menos frontal. Nessas dinâmicas, tridimensionalidade, direções múltiplas e mesmo um grau mais elevado de jogo - de liberdade na criação, é possível afirmar - são fatores que convidam a um olhar mais desprendido. Isso, aliás, costuma acontecer naturalmente.

De maneira geral, vale ter em mente que o trabalho com o olhar é um caminho de pesquisa, de autoconhecimento, e não uma fórmula; em outras palavras: é um princípio pedagógico, e não uma determinação formal. O apaziguamento tanto do olhar quanto da expressão facial está relacionado com a retirada destes de uma posição superior que costumam ter em interpretações de estilo realista, propiciando um caminho de desierarquização das partes do corpo 
e das vias para o jogo cênico.

Não obstante, reconhecemos uma possível narrativa histórica para justificar essa confusão tão recorrente a respeito do olhar na prática do Viewpoints. Esta questão seria, inclusive, apenas um sintoma de outra questão mais ampla à qual tornaremos mais adiante: as regras do jogo. Muitos dos trabalhos da dança norteamericana pós-moderna - na década de 1960, principalmente em Nova Iorque, com a centralidade do Judson Dance Theater - continham de fato um grau de frieza porque em diferentes medidas estavam se opondo à alta carga expressiva, emotiva, psicológica, da dança moderna.

Yvonne Rainer, uma das figuras centrais do Judson, sintetizou teoricamente sua "estética da recusa" no icônico No Manifesto, de 1965. Quanto à sua criação artística, convém lembrar "Trio A", de 1966 - parte do trabalho The Mind is a Muscle. Nesta dança curta e com movimentos interligados em qualidade aparentemente cotidiana, há uma regra bem clara definida pela coreógrafa: os dançarinos não devem olhar para o público, nunca. Como esclareceu Rainer (1995, p.271), "[o]u o olhar era desviado ou a cabeça estava engajada no movimento. O efeito desejado era uma apresentação mais funcional, ao invés de uma apresentação expositiva [ou exibida]"8.

“'Nós não queríamos emocionar', explica Paxton. 'Por outro lado, o olhar vidrado estava obviamente se tornando ou já havia se tornado um clichê"” (Banes, 1993, p. 43). Conclui-se que a busca pela neutralidade quase apática do rosto em tantos trabalhos do período é possivelmente a razão da generalização de que a prática do Viewpoints levaria a uma atitude maquinal, automática. Mas, se naquele momento a questão do olhar e da frieza eram preocupações estéticas da geração, hoje não são prioridade, muito menos no que se refere ao viewpoints, por mais que esta seja uma técnica intrinsecamente ligada à dança pós-moderna em seu status nascendi.

${ }^{7}$ A expressão, de Sally Banes, é citada em “O que é uma dança atual? Yvonne Rainer” (Gil, 2004). 


\section{Scores, improvisação e contemplação}

Para a compreensão da gênese do Viewpoints, é mister pensar na chegada de Mary Overlie em Nova Iorque na década de 1970. Quanto à década de 1960, esta foi marcada pela influência de John Cage em muitas esferas da arte, que resumidamente pode ser caracterizada pelo influxo da filosofia do zen budismo, pela interdisciplinaridade ${ }^{9}$ e pela criação artística através de scores - partituras ou tarefas - e procedimentos de acaso. Já a década de 1970 teve como uma de suas tônicas, na cena nova iorquina, a improvisação. O Grand Union (1970-1976), coletivo de improvisação, foi uma decorrência direta do Judson Dance Theater, tendo como ponto intermediário o projeto Continuous Project Altered Daily, capitaneado por Yvonne Rainer e apresentado em 1970 no Whitney Museum.

Foi nesse contexto que Overlie chegou a Nova Iorque e estabeleceu parceria principalmente com Barbara Dilley, responsável direta por sua decisão de ali viver e com quem, em 1972, formou o grupo de improvisação The Natural History of The American Dancer, que contava com outras cincos dançarinas. Overlie (2016) conta que, nesse contexto, via os seis viewpoints emergirem nos ensaios silenciosos no icônico edifício do número 112 da Greene Street a partir do engajamento físico com a dança, na ausência de comunicação verbal. A coreógrafa também pontua a importância, naquele momento, das trocas entre artistas de diversas linguagens - quase sempre sob a tônica da desconstrução - , fosse em projetos de parceria, na fruição de obras ou, ainda, em trocas de cunho mais pessoal, até mesmo íntimo.

Outra parceria estabelecida por Overlie muito citada em seu livro foi com Steve Paxton, que no mesmo ano de 1972 começou a desenvolver sua Contact Improvisation - técnica utilizada por Overlie em suas aulas na Experimental Theater Wing da NYU juntamente à Hamilton Floor Barre ${ }^{10}$. Barbara Dilley, em 1974, foi contratada para lecionar na Naropa University, onde desenvolveu a Contemplative Dance Practice, pesquisa de aproximação da dança com a

\footnotetext{
9 Ou mesmo pela indisciplina, como inferem Almeida e Olinto (2017), através das múltiplas proposições desviantes de Cage, radicalmente fora das regras e padrões estabelecidos.

10 Overlie (2016) explica que somava à prática do Viewpoints técnicas corporais que não fossem formais/formatadas (como é o balé clássico ou mesmo algumas técnicas modernas), mas que trabalhassem através das sensações. A coreógrafa cita também o Body-Mind Centering, de Bonnie Bainbridge Cohen.
} 
meditação. Estavam em voga a meditação, a contemplação, a buscar pela reconexão com a Natureza. A própria Mary Overlie estudou Transcendental Meditation com Maharishi Mahesh Yogi, tornando-se inclusive professora da prática, fator que influenciou sua concepção dos Six Viewpoints. Pensamos também nas práticas de contemplação dos elementos da natureza de Anna Halprin em seu deck nos arredores de São Francisco e em Simone Forti observando os animais em suas idas ao Giardino Zoologico di Roma, em uma breve temporada de retorno à Itália.

Muitas danças avant garde daquele período oscilavam entre estes três caminhos de criação díspares, mas possivelmente complementares: 1) a organização coreográfica a partir de scores (somada a procedimentos de acaso), 2) a improvisação e 3) a contemplação (o espírito meditativo). Tais vias de criação - que reúnem, em si, questões filosóficas e políticas mais amplas - estavam imersas no zeitgeist dos sixties, com sua intensa onda de orientalismo, inúmeros movimentos sociais utópicos de luta por liberdade e igualdade (social, de gênero, de raças) e manifestações antiviolência contrárias à Guerra do Vietnã¹.

Sobre o Judson, especificamente, o interesse maior estava no processo de criação coreográfica a partir das noções de score e acaso, advindas de John Cage - tônicas do curso de Robert Dunn de composição para coreógrafos -, e da ampliação daquilo que poderia ser considerado dança ou mesmo arte. Entre 1962 e 1964, dos dezesseis concertos de dança apresentados ao público no contexto do Judson, apenas um teve como foco a improvisação: o concert \#14, em 27 de abril de 1964.

Partindo desse breve esquema da dança avant garde norte-americana nas décadas de 1960 e 1970, é possível analisar a improvisação em Viewpoints por analogia e perceber nela estas três energias ou forças motrizes: 1) as tarefas (scores), as regras, o elemento apolíneo, frio; 2) a improvisação, o jogo, o elemento dionisíaco, quente e 3) a via contemplativa.

Miriam Rinaldi, em sua tese de doutorado intitulada “Teoria e Prática do 
Viewpoints" (2016), analisa o período no qual Mary Overlie originou o Viewpoints a coreógrafa assim preferia, ao invés de dizer que o havia "inventado". No campo estético, partindo das artes visuais, Rinaldi localiza as citadas forças motrizes que aqui organizamos de maneira ligeiramente diferente - em duas vertentes da arte norte-americana do período: o minimalismo de um lado e a action painting com seu efeito all over do outro (sendo esta um reconhecido antecedente dos happenings de Allan Kaprow).

[...] de um lado a arte orgânica, sem fronteiras distintas entre vida e obra, de Allan Kaprow, e de outro a arte imparcial dos minimalistas, focada sobretudo na recepção e no papel do espectador evidenciado nos textos e nas experimentações de Robert Morris. Esses extremos sintetizam de forma exemplar o espírito de uma época e suas aspirações, compondo um terreno fértil para compreender o contexto e o surgimento da técnica do Viewpoints (Rinaldi, 2016, p.35).

Embora seja sempre apontado como uma arte visualmente fria e racional o que não deixa de ser -, o minimalismo é abordado por Rinaldi através do conceito de presentidade (presentness), como apresentado por Robert Morris em "O tempo presente do espaço", de 1978. Com isso, a atriz e pesquisadora lança luz à questão da recepção, do envolvimento cinestésico do espectador quando na presença de uma obra minimalista e da relação deste não apenas com as dimensões do tempo e do espaço, mas também da memória. Como apresenta Rinaldi (2016), Morris defende que o fruidor, quando perante uma obra de arte despida de tema e detalhes, mergulha para dentro de si, em um exercício mnemônico por vezes abissal. Isso, transposto para a improvisação em Viewpoints - também por vezes "esvaziada" de um tema ou de emoções facilmente perceptíveis - e para os próprios praticantes, parece clarear a dimensão meditativa exposta acima, que acarreta menos ação e mais contemplação.

Se as improvisações em Viewpoints são por vezes taxadas de frias por conta de suas regras rigorosas e seu caráter minimalista, esta é apenas uma face da moeda. A improvisação pode - e deveria - ter calor, elã e espírito lúdico! Um sorriso ou uma lágrima fortuita, assim como o olhar, são ações expressivas e podem, claro, fazer parte da improvisação. Porém, deve-se manter a devida atenção para o reconhecimento de padrões ou mesmo vícios do ator quando em 
cena. Neste sentido, o Viewpoints é uma poderosa ferramenta de crescimento, "um medidor de suas próprias forças e fraquezas, para a descoberta do quanto você está livre e do quanto está inibido, quais são seus próprios padrões e hábitos" (Bogart e Landau, 2017, p.38).

\section{As regras e o jogo. As regras do jogo}

O sistema de improvisação Viewpoints, principalmente como organizado por Bogart e Landau, configura o que Trisha Brown chamou, já no início da década de 1960, de improvisação estruturada:

[quando] no início você define uma estrutura e decide lidar com os materiais $X, Y$ e $Z$ de uma certa maneira, fixa ainda mais e diz que você só pode andar para frente, não pode usar a voz ou tem de fazer 195 gestos antes de bater na parede do outro lado da sala, isto é uma improvisação dentro de limites definidos (Banes, 1993, p.20)12.

Tal colocação vai ao encontro do espírito desconstrucionista que Mary Overlie reconheceu no cenário artístico de Nova lorque quando ali chegou e apontado por Miriam Rinaldi (2016) na pesquisa artística dos assim referidos minimalistas e na influência destes no universo da dança. A originadora dos Six Viewpoints diz de maneira clara como os seis pontos de vista que nomeou SSTEMS - space, shape, time, emotion, movement, story ${ }^{3}$ - são os materiais básicos do teatro desconstruido, um termo chave do pós-modernismo, base filosófica da prática do Viewpoints (ainda que não seja exatamente uma escola) segundo a coreógrafa.

A prática improvisacional de Overlie propõe a criação cênica por meio da particularização $^{14}$ e do exame minucioso dos componentes, um caminho

12 [...] in the beginning you set a structure and decide to deal with $X, Y$, and $Z$ materials in a certain way, nail it down even further and say you can only walk forward, you cannot use your voice or you have to do 195 gestures before you hit the wall at the other end of the room, that is an improvisation within set boundaries.

13 Os seis viewpoints de Overlie serão aqui sempre apresentados no original em inglês para facilitar a diferenciação, no decorrer do artigo, em relação aos nove viewpoints de Bogart e Landau.

${ }^{14}$ Overlie afirma usar o termo particalization como uma extensão do substantivo particle (partícula) e não como a ação de tornar particular, próprio - ainda que ambas as noções possam ser interligadas. Se transposto o raciocínio para o português, o verbo particularizar deveria ser entendido como derivado do substantivo partícula, com uma compreensão de dividir, tornar menor, e não como derivado de particular, no sentido de próprio, peculiar, distinguido. 
constante de desconstrução e reintegração dos materiais. Segundo ela, "o coração do Pós-modernismo encontra-se na microscópica atividade de diferenciação" (Overlie, 2016, p. 87), afirmação ancorada nos termos da filosofia da diferença e que fundamenta a noção de news of a difference, cara a Overlie.

O estudo aprofundado do estar em cena, dos elementos constituintes da cena e das nuances, das pequenas diferenças e transformações, só é possível pela existência de regras. Uma improvisação totalmente livre, sem balizas, não possibilitaria o grau de aprofundamento no deslindamento do fazer cênico como o faz uma improvisação estruturada. Isso explica o minimalismo radical do Viewpoints, seu espírito reducionista e suas regras bem definidas; as aparentes limitações. "Mas eu só posso andar e mais nada?" Sim, em certos enunciados, o único vocabulário de ação é o caminhar, e isso não é pouco. É uma questão de calibragem de atenção, de percepção de nuances; uma questão de notar as mínimas diferenças, como convida Overlie. Não se trata, portanto, de limitar o jogo, mas de reduzir e particularizar os parâmetros com o intuito de atingir um nível maior de aprofundamento e detalhamento.

Todo jogo tem regras. É o jogo que as tem, e não elas que detêm o jogo. Incontáveis vezes a questão da desobediência às regras surgiu em conversas ao final das práticas sob nossa condução no Núcleo Experimental, e se trata verdadeiramente de uma questão relevante. Mas, quando alguém pergunta “Tudo bem termos quebrado as regras?”, algum(a) colega costuma já apresentar o argumento complementar: "Mas estávamos tão conectados! Foi uma decisão coletiva”. As falas têm pequenas variações, mas seguem quase sempre essa linha. Ora, já está tudo dito. As regras são importantes? Sim, são essenciais. No entanto, como já afirmamos, elas servem ao jogo, e não o oposto.

O jogo do Viewpoints diz respeito à escuta, à conexão com o coletivo, à fina percepção de eventos que já estão acontecendo com determinados corpos, em determinado espaço e determinado tempo. "[...] o tema central de toda improvisação em Viewpoints é a busca pelo consenso. Sem falar, o grupo encontra um caminho divertido e engenhoso para resolver a tarefa" (Bogart e Landau, 2017, p.109). 
Mas, voltando às regras, retornamos a dois artistas que foram influências diretas para a dança e o teatro do cenário norte-americano da segunda metade do século XX. Tanto Anna Halprin quanto John Cage trouxeram regras, dito de modo geral, para dentro da prática artística como caminhos de criação em oposição à genialidade, à virtuosidade e mesmo à expressividade, objetivando uma aproximação da arte com a vida. O que estamos nos referindo genericamente como regras era por ambos referido como scores, que são, em tradução literal, partituras musicais - representações gráficas que dão origem a uma música. Cada artista encarava as scores com especificidades, porém.

No caso de Halprin, cremos ser mais bem compreendido o procedimento quando utilizado o termo "tarefa" (task). A pesquisa de movimentos, para a coreógrafa, poderia partir de tarefas tão simples quanto carregar um tronco ou uma pessoa, ou observar algum elemento da natureza e buscar traduzir isso corporalmente. O foco estaria na percepção do que se passava com o corpo ao cumprir tais tarefas, mais do que em qualquer juízo ou intenção estética dada a priori. A criação de Halprin se dava basicamente a partir de improvisações, com diferentes graus de estruturação, e mesmo quando formalizando trabalhos coreográficos, estes eram fundamentalmente organizados por tarefas - portanto, ainda com um grau de improvisação -, aproximando a arte da vida e fazendo ver (e viver) como, rigorosamente, qualquer coisa poderia virar dança.

Na icônica Paredes and Changes (1965), as tarefas eram ações tão ordinárias quanto caminhar, correr, despir-se e se vestir novamente determinadas vezes ou rasgar uma grande quantidade de papel pardo e lançar os pedaços ao alto. Na linha do que Halprin já afirmou de variadas maneiras, as tarefas the dizem o que fazer, mas não the dizem como, e muito menos o que você irá sentir ao cumprilas. Isso, a nosso ver, está de acordo com o uso de tarefas durante a prática do Viewpoints. Trata-se, primordialmente, de como um coletivo alcança determinado objetivo a partir de uma escuta e conexão refinadas dos indivíduos. Os significados e sensações decorrentes das ações cênicas surgem da minuciosa consciência com que estas são executadas, deslocando-as do tempo-espaço cotidiano.

Já no caso de Cage e Robert Dunn, a noção de scores é majoritariamente 
(mas não exclusivamente) a noção de "partitura" enquanto notação gráfica15, mas não se limitando à ordenação de notas musicais: "um tipo particular de notação musical que não mais necessariamente apresentava notas musicais em suas pautas. Essas partituras apresentavam desenhos, notações gráficas, como pontos ou linhas e, também, números e palavras" (Almeida e Olinto, 2017, p.23).

Sally Banes (1993) explica que, em seu workshop de composição para coreógrafos - ocorrido entre 1960 e 1962 e que deu origem ao Judson -, Dunn propunha criações coreográficas a partir do uso de partituras musicais não por suas sugestões sonoras - suas melodias -, mas por suas estruturas temporais, rítmicas, na esteira da ênfase dada por Cage às durações. A partir desta lógica, outras partituras, desenhos, gráficos, mapas, entre outros, serviram de ponto de partida para as criações. No entanto, por vezes, as scores de Dunn podiam, sim, ser entendidas como tarefas (e não como notações gráficas, como argumentamos); por exemplo, quando eram propostas pelo professor scores como "Faça uma dança de 6 minutos" ou "Faça uma dança de 5 minutos em meia hora".

Era frequente uma score ser feita por um(a) coreógrafo(a) para que outra pessoa dançasse a partir dela, o que reitera a autossuficiência necessária do objeto, em si, das palavras e/ou imagens ali reunidas. No contexto do Judson, Yvonne Rainer, mas não apenas ela, desenhou padrões topográficos somados a números e palavras designando ações. Elaine Summers chegou a usar um rabisco de seu filho como partitura para uma dança executada por Ruth Emerson. Já esta última desenvolveu um gráfico (uma score) para Narrative, uma coreografia coletiva em três partes:

Cada dançarino recebeu uma score que indicava os padrões de caminhada [walking patterns, o que no Viewpoints diz-se topografia], foco e andamento [tempo], e também as deixas para ações baseadas em ações dos outros dançarinos. As instruções não são dramáticas ou psicologicamente descritivas; elas se referem a movimentos abstratos e focos individuais, ao invés de interação. Por exemplo, as instruções para o dançarino B (Paxton) incluem a diretiva "Tome muito cuidado para

15 É importante não confundir esta tradução de scores em "partituras" com a noção comum na dança de partitura enquanto sequência de movimentos, construção de frases coreográficas. 
nunca focalizar em G (Rainer) ou direcionar seus movimentos para ela". Três dos dançarinos caminharam ao longo de trajetos geométricos durante a primeira parte [topografia, uma vez mais]: Paxton ao longo de diagonais, Dunn ao longo de um retângulo e Summers em um círculo; McDowell caminhou aleatoriamente para trás e Rainer caminhou aleatoriamente para os lados. O foco para cada dançarino era bastante específico, e cada um tinha que ajustar seu andamento ao ritmo dos outros dançarinos (Banes, 1993, p.41-42) ${ }^{16}$.

As scores têm sido utilizadas desde a década de 1950 - com Cunningham, por exemplo - na criação de situações de performances frente a uma plateia. Diferentemente, na prática do Viewpoints, as scores são utilizadas enquanto estratégia pedagógica, sendo geradoras de dinâmicas de improvisações quando, por exemplo, delimitam topografias - corredores, quadrantes, uma grade etc. ou delimitam ações, como acontece no exercício das entradas e saídas. Tais exemplos estão presentes no livro de Bogart e Landau. Mas o Viewpoints é uma maneira versátil de pensar e organizar a prática cênica, e seus exercícios podem ser desdobrados, recriados. "Viewpoints é um processo aberto e não uma técnica rígida. Esperamos que este livro seja para você não um fim, mas um começo" (Bogart e Landau, 2017, p. 3).

Em nossa condução, por exemplo, é comum que as dinâmicas de improvisação contem com scores adicionais - chamamos "tarefas coletivas" - a serem cumpridas em jogo sem planejamento prévio. A lógica dos ingredientes (originalmente, da composição) é transposta para as várias dinâmicas de improvisação. Assim, além de dar conta das regras próprias de cada jogo, a escuta e a ação dos performers veem-se engajadas em obter êxito em tarefas variadas como: uma longa pausa, um salto, um ápice de velocidade, uma diagonal, uma queda, e por aí vai, sempre a serem realizadas coletivamente e em uníssono (sem que uma ação individual indique o instante). Esta lógica compositiva durante as improvisações será retomada mais adiante, na última parte deste artigo.

${ }^{16}$ Each dancer was given a score that indicated walking patterns, focus, and tempo, and also cues for action based on the other dancers' actions. The instructions are not dramatic or psychologically descriptive; they refer to abstract movements and individual focus, rather than interaction. For instance, directions to dancer B (Paxton) include the directive 'Take great care never to focus on G (Rainer) or direct your movement at her.' Three of the dancers walked along geometrical paths during part one: Paxton along diagonals, Dunn along a rectangle, and Summers along a circle; McDowell walked at random backwards, and Rainer walked at random sideways. The focus for each dancer was quite specific, and each one had to cue his or her tempo to the rates of the other dancers. 
Do momento histórico de inúmeras transformações estéticas, e mesmo institucionais, da geração Judson - que rapidamente alargou as fronteiras da dança, inclusive dentro de espaços culturais mais tradicionais -, as regras foram transpostas para o Viewpoints em um território de encontro da estética com a pedagogia. As regras existem no Viewpoints para possibilitar um caminho desierarquizado de pesquisa no qual a busca do performer deixa de ser por uma ideia ou emoção prévia a ser resolvida formalmente e passa a ser um caminho lúdico de descobertas da potência expressiva da própria presença dos corpos em situações de jogo. Como diz Overlie (2016, p. 3), "[o]uça e veja o que já existe, em vez de tentar manipular um material em algo que se pareça com arte, teatro ou dança para você"»17.

Para encerrar a questão das regras e do jogo, evocamos Cage, que em seu texto "Graça e clareza", originalmente publicado na revista Dance Observer, em 1944, após defender a importância da clareza enquanto estrutura temporal - que em nossa linha de pensamento estaria associada à noção de regras -, diz:

Junto à clareza da estrutura rítmica, a graça forma uma dualidade. Juntas elas têm uma relação como aquela entre o corpo e a alma. A clareza é fria, matemática, desumana, porém básica e terrestre. A graça é quente, incalculável, humana, oposta à clareza, e como o ar. Graça aqui não significa beleza; ela é usada para significar o jogo com e contra a clareza da estrutura rítmica. Juntas, as duas estão presentes nos melhores trabalhos das artes do tempo, incessantemente, dando vida, opostas uma à outra (Cage, 2019, p.91-92 - grifo nosso).

\section{Nove com seis, onze}

De nossa experiência no treinamento intensivo de verão da SITI Company, uma das coisas mais marcantes foi como a condução da prática do Viewpoints misturava os seis viewpoints originais de Overlie com os nove viewpoints organizados por Bogart ${ }^{18}$, oscilando livremente entre os dois sistemas, trabalhando

\footnotetext{
${ }^{17}$ Listen and see what already exists, instead of trying to manipulate a material into something that looks like art or theater or dance to you.

${ }^{18}$ Objetivando a fluidez da leitura, a partir deste ponto os nove viewpoints organizados por Anne Bogart e Tina Landau, e praticado continuamente pela Siti Company, serão referidos como "os viewpoints de Bogart" ou "os nove viewpoints".
} 
com noções e enunciados de ambos. Os membros da companhia que estavam à frente da condução - Will Bond e G. M. Gianino - pareciam ainda fruir com frescor, prazer e gratidão os ensinamentos de Mary Overlie presentes em seu tardio e único livro, publicado não muito antes, em 2016.

A primeira prática do Viewpoints proposta por Gianino foi a prática "Walking and Stopping in Space" (Overlie, 2016, p.145). Não foi dito, na situação, que o exercício proposto era de Overlie (e não de Bogart, diretora da companhia), e, sinceramente, isso não nos pareceu ou parece ser uma questão. As práticas dos seis ou dos nove viewpoints em muito se assemelham, claro, e podem inclusive ser intercruzadas, como ocorreu nessa ocasião. Com a prática já mais avançada e a turma mais conectada, os condutores propuseram uma longa sequência de sessões de open Viewpoints nas quais improvisavam geralmente cinco ou sete pessoas, por cerca de cinco minutos. Dentro da técnica, estas são as situações mais próximas de improvisações livres. No entanto, a cada sessão foram definidos dois viewpoints como focos da pesquisa e, novamente, houve ali a utilização tanto dos seis quanto dos nove viewpoints, sem grandes diferenciações e, definitivamente, sem hierarquização.

Acreditamos que a junção dos viewpoints de ambos os sistemas pode ser utilizada na condução de práticas, contanto que seja enriquecedora para os participantes - e isso, entretanto, está de acordo com as sensações subjetivas de quem está conduzindo (ou também praticando, claro). O limite para tal "cruzamento" é quando as regras passam a ficar pouco claras. No contexto do Viewpoints, regras pouco claras não dão jogo. É de suma importância a clareza de quais parâmetros estão sob escrutínio e através de quais dinâmicas.

Em nossa prática junto às turmas do Núcleo Experimental do Sesi, a linha guia de condução segue sendo os nove viewpoints de Bogart, pois este sistema apresenta propostas práticas mais claras e com maior variação de dificuldade enquanto focos de atenção. Tal variação permite mais nuances e possibilidades na construção das sequências didáticas, o que é essencial, principalmente, para quem conduz pesquisas de longa duração. Contudo, temos feito um trabalho de incluir noções propostas por Overlie em nossa prática, com a sensação e a crença de que isso é enriquecedor para os praticantes. 
Dos seis viewpoints de Overlie, três são muito próximos dos viewpoints de Bogart: space, shape e time. Space é subdividido em três dos nove viewpoints: arquitetura, topografia e relação espacial. Shape está relacionado tanto à forma quanto ao gesto dos nove viewpoints. E time é subdividido em quatro parâmetros: andamento, duração, resposta cinestésica e repetição' ${ }^{19}$.

Dos SSTEMS, sobram, portanto, os três últimos: emotion, movement e story. Movement, para Overlie (2016), diz respeito a como você sente o espaço a partir de sua movimentação; diz respeito à habilidade de experienciar o movimento pela sensação. Este viewpoint diferencia-se bastante dos viewpoints de Bogart, mas, por uma decisão mais intuitiva do que racional, não o inserimos em nossas conduções. As duas noções que, sim, temos trazido para a prática são as noções de emotion e story. Não coincidentemente, estes dois parâmetros específicos são menos materiais de criação e mais operações ou percepções.

A noção de emotion nos Six Viewpoints muito se diferencia da noção de emoção para o teatro dramático - um teatro que parte de uma dramaturgia, majoritariamente com uma fábula, com suas personagens, intenções e conflitos pré-definidos. Segundo Overlie, emotion é a presença do performer quando em jogo, em cena; é uma autoconsciência ativa e sempre em mutação: "Tornar-se presente é tomar consciência da mente e do corpo deslocando-se como areias no deserto" (Overlie, 2016, p.29). ${ }^{20}$ Performando sua própria presença, o performer existe em sua completude, naquele determinado momento, assim também se apresentando aos parceiros ou a uma possível plateia sem proteção ou barreiras - pensamento próximo à via negativa grotowskiana - , permitindo ser visto e lido na inteireza de sua humanidade, com suas fragilidades e potências.

As possíveis emoções que surgem neste caminho, neste exercício de estar presente a todo instante, são emoções que interpelam o performer, que nascem na fugacidade do instante, e não de um conflito estabelecido de antemão. Sem planejamento ou intenção prévios, as emoções na concepção de Overlie irrompem inadvertidamente no performer. Isso está em concordância com o fato de o

\footnotetext{
${ }^{19}$ A articulação entre os dois sistemas aqui estabelecida é inferência nossa oriunda tanto da análise do aporte teórico aqui em debate quanto de nossa experiência prática.

${ }^{20}$ Becoming present is to become aware of the mind and body shifting like sands in a desert.
} 
Viewpoints lidar com o que já está dado na realidade da presença de determinados corpos coabitando um mesmo espaço-tempo. No Viewpoints, trata-se menos de intencionar, criar, propor, e mais de se tranquilizar, perceber e responder.

Bogart e Landau (2017, p. 103) têm uma sintética, mas significativa, colocação a respeito da emoção (que não consideram um viewpoint) em seu livro, e que se relaciona também com reflexões já feitas anteriormente neste artigo:

O maior ganho dos Viewpoints é que eles não guiam você para longe da emoção. Muitas vezes, as pessoas confundem o objetivo com um estado de neutralidade e apatia, em oposição a um estado de vivacidade, receptividade e experiência. O que importa é lembrar que os Viewpoints têm exatamente, assim como outros "métodos" de atuação, o objetivo de fazer com que você esteja vivo e engajado no palco. A beleza dos Viewpoints é que eles nos permitem alcançar essa meta, não nos forçando a isso, mas recebendo dos outros e de nós mesmos.

Quanto ao viewpoint story, ele difere da noção de história enquanto narrativa, fábula, portanto da noção de história para o teatro de matriz dramática, bem como para o ballet clássico ou mesmo a dança moderna. Story para Overlie é sinônimo de lógica, de sequenciamento de informações.

Como seres humanos, nós reflexiva e bem-sucedidamente classificamos toneladas de informações diariamente, formulando uma história viva e contínua. Este material, interrogado como um fenômeno natural, transforma-se em partículas, que se transformam em um arranjo dessas partículas, expondo a manipulação da lógica, cerne de Story (Overlie, 2016, p. 43 - grifo nosso $)^{21}$.

Ou seja, toda nossa maneira de nos relacionarmos com o mundo, segundo a coreógrafa, se dá através de lógica. Para Overlie, em arte, não se daria de maneira distinta, haveria uma lógica subjacente a todas as obras. No caso de obras figurativas ou narrativas, a lógica seria a história, o tema, o que é talvez mais fácil de compreender. Mas, mesmo no caso de obras de arte abstratas, haveria uma lógica. Por exemplo, a lógica da textura, do espaçamento entre os elementos, da relação entre as cores, pensando em pinturas; a lógica do tempo das ações, de

${ }^{21}$ As human beings we reflexively and successfully sort tons of information on a daily basis, formulating a living ongoing story. This material, interrogated as a natural phenomenon, turns into particles that turn into an arrangement of those particles, exposing the manipulation of logic that is the core of Story. 
repetições, de padrões espaciais, no caso de obras cênicas.

Na esteira do dadaísmo, John Cage, na música, e seu parceiro Merce Cunningham, na dança, seguiram por um caminho de composições aleatórias através de procedimentos de acaso com o uso do /-ching ou de maneiras mais prosaicas, como lançando um dado para cima ou mesmo uma moeda.

Artistas como Cage zombavam das formas antiquadas e restritivas da história [Story enquanto narrativa]. Esses artistas estavam tentando fazer com que o público prestasse atenção a uma esfera mais ampla. Eles estavam encenando um ataque total à posição dominante e hierárquica da história nas artes cênicas. Em defesa e delimitação de seu território, sua declaração era: isto não significa nada. Esta afirmação tinha e tem como intenção redirecionar nossa atenção para uma vasta gama de sons, lógicas, estruturas, espaços, movimentos, formas, tempos, dimensões (Overlie, 2016, p. 45) 22.

No entanto, ainda que se sentisse participante da mesma geração e com aspirações e intenções artísticas próximas às de Cage e outros, Overlie não concordava com a questão da ausência total de sentido. A seu ver, toda obra de arte significa algo na medida em que é criada através de escolhas lógicas. Segundo ela, a escolha da utilização do termo Story como um de seus seis viewpoints, e não Logic (lógica), teria sido, portanto, quase uma provocação à geração antinarrativa, antiemoção; um posicionamento radical a favor da criação artística enquanto um ato consciente e de essência lógica, mesmo quando abstrata. "Uma tela branca com um ponto preto está lidando com lógica. Se o ponto está centralizado, ele tem um impacto diferente sobre nós do que se fosse colocado em qualquer uma das milhões de outras posições possíveis" (Overlie, 2016, p. 50)²3.

Esclarecidos os conceitos de Overlie, retomamos a hipótese de que o viewpoint emotion seria menos um material com o qual o performer lida quando em jogo e mais algo que ele percebe ou sente, algo pelo qual é interpelado. Já o

${ }^{22}$ Artists like Cage scoffed at the old-fashioned and confining forms of Story. These artists were trying to get the audience to pay attention to a larger sphere. They were staging an all-out attack on the dominating and hierarchical position of Story in performing arts. In defending and staking out their territory their statement was: this does not mean anything. This statement was, and is meant, to redirect our attention to a vast array of sounds, logics, structures, spaces, movements, shapes, times, dimensions.

${ }^{23}$ A white canvas with a black dot is dealing with logic. If the dot is centered, it has a different impact on us than if it were placed in any of the millions of other possible positions. 
viewpoint story seria uma operação constante: a contínua leitura da lógica do presente, a percepção das diferenças e dos movimentos, para que escolhas sejam feitas frente às opções que se apresentam ao performer. Por estes motivos, acreditamos na potência da absorção destes dois viewpoints no sistema de improvisação com os nove viewpoints de Bogart. Por se tratar menos de materiais a serem articulados e mais de princípios para se ter em mente quando jogando, estes dois viewpoints não interferem nas regras dos diversos exercícios/jogos e, como temos percebido nos depoimentos dos atores e atrizes, tendem a enriquecer a experiência da prática.

Dito isto, percebemos que unir todos os quinze viewpoints (dos dois sistemas de organização) talvez não seja um caminho produtivo na pesquisa cênica. Como já foi dito, a semelhança ou proximidade entre alguns dos quinze viewpoints poderia acarretar pouca clareza nas regras das improvisações, no trato com o material. No entanto, trabalhar com onze viewpoints - os nove de Bogart somados a emotion e story de Overlie - tem se mostrado um caminho profícuo.

\section{Improvisação e composição}

O Livro dos Viewpoints, de Anne Bogart e Tina Landau, tem como subtítulo "um guia prático para viewpoints e composição". Já de saída, as autoras criam uma diferenciação: uma coisa é o Viewpoints - "uma filosofia traduzida em uma técnica" (2017, p.25) de improvisação cênica a partir de nove parâmetros ou pontos de vista - e outra coisa é a composição.

Segundo as autoras, composição é um método para criar trabalhos, para praticar o arranjo de elementos no tempo e no espaço. "Composição é para o criador (diretor, escritor, performer, designer etc.) o que o Viewpoints é para o ator: um método para praticar arte" (Bogart e Landau, 2017, p.32). Claro, nada impede que diretores(as) também pratiquem Viewpoints, no entanto, a composição permite um cruzamento maior com as outras esferas do fazer teatral iluminação, sonoplastia, dramaturgia, direção de arte etc. - e com outras linguagens artísticas.

Se comparada ao Viewpoints, a composição estaria um passo à frente no 
acabamento, na antevisão e na preparação da coisa cênica, isso porque a prática em Viewpoints é sempre uma improvisação. Enquanto vocabulário, os nove viewpoints podem ser utilizados em qualquer situação ${ }^{24}$, mas, enquanto prática, pesquisa cênica, treinamento de atores e atrizes, trata-se sempre de dinâmicas de improvisação.

Já a prática da composição, por outro lado, tem um grau a mais de programação. Para uma composição, o grupo de artistas participantes lembrando que aqui as autoras agregam todos os criadores - tem um tempo curto para solucionar cenicamente uma lista de tarefas (uma score!) ou, como dizem as autoras, uma lista de ingredientes. Tal lista pode ser mais fechada em si mesma, enquanto exercício do fazer cênico, ou já voltada para a montagem de uma peça. Vale notar que há sempre um grau de improvisação mesmo numa composição, visto que, por conta do tempo exíguo de criação - uma "pressão delicada”, como dizem as autoras -, o ensaio nunca deve ser suficiente para de fato fixar totalmente as propostas cênicas. "Margem de erro: margem de liberdade"25.

A divisão didática entre Viewpoints e composição é, de fato, positiva, pedagogicamente falando. Para praticar composição, é interessante - ou mesmo necessário - que o coletivo de performers já esteja operando com maturidade e tranquilidade a partir dos viewpoints. No entanto, já há na própria prática do Viewpoints o treinamento - no sentido da percepção, sensibilização e aguçamento - do olhar compositor.

Estamos chamando de olhar compositor a capacidade ou a atitude de ver/ler - com plena atentividade ${ }^{26}$ - os elementos que estão a compor o espaço cênico em um determinado tempo e de responder a isso criativamente: sensação e reação; percepção e resposta. A prática do Viewpoints demanda que o jogador a

\footnotetext{
${ }^{24}$ Por exemplo, mesmo numa temporada, os viewpoints podem ser um vocabulário em comum da equipe: "Hoje a velocidade do espetáculo estava muito baixa”; "A arquitetura deste espaço novo é diferente, teremos de reestruturar a topografia da peça”.

${ }^{25}$ Versos finais do poema "Errância", de Orides Fontela: "Só porque / erro / encontro / o que não se / procura // só porque / erro / invento / o labirinto // a busca / a coisa / a causa da / procura // só porque / erro / acerto: me / construo. // Margem de / erro: margem / de liberdade".

${ }^{26}$ Retomando o circuito da primeira reflexão: soft focus, visão periférica e escuta extraordinária.
} 
todo instante leia a configuração do espaço e a lógica subjacente às movimentações. O praticante do Viewpoints desenvolve a habilidade de fazer e se ver fazendo, sincronicamente. Como disse Grotowski (2015, s.p. - grifo nosso):

Nos textos antigos é possível ler: Nós somos dois. O pássaro que bica e o pássaro que olha. Um vai morrer, um vai viver. Preocupados em bicar, e embriagados com a vida dentro do tempo, esquecemos de fazer viver aquela parte de nós que olha. Então, há o perigo de existir apenas dentro do tempo e, de modo algum, fora do tempo. Sentir-se olhado por essa outra parte de si (aquela que parece estar fora do tempo) traz outra dimensão. Existe um Eu-Eu. [...] Eu-Eu não significa estar cortado em dois, mas ser duplo. Trata-se de ser passivo ao agir e ativo ao olhar (ao contrário do habitual). Passivo: ser receptivo. Ativo: ser presente.

De maneira semelhante, Overlie refere-se ao praticante do Viewpoints sempre como observador/participante. Estar no tempo, mas também fora dele, diz Grotowski; estar no espaço, mas também fora dele, é possível inferir. O Viewpoints preconiza um performer presente, sensível ao que já está acontecendo - porque há rigorosamente sempre algo acontecendo ${ }^{27}$. No entanto, há mais de uma dimensão temporal existente, no que concerne à ação do performer quando em jogo; e, para esclarecê-las, evocamos as noções de feedforward e feedback.

A maneira mais simples e direta de compreender o feedforward é como a capacidade de antever algo que vai acontecer no futuro imediato, como quem “antecipa a necessidade de agir” (Bogart e Landau, 2017, p.52). É graças a esta habilidade que, numa improvisação, conseguimos estar em perfeita sincronia com um parceiro em alguma ação, acarretando aquela sensação de "Uau, parece que isso estava combinado!". Esta habilidade é muito requisitada nos exercícios introdutórios da prática do Viewpoints, mas é também essencial posteriormente, nas dinâmicas mais complexas. Com o passar do tempo, quando em prática constante do Viewpoints, o feedforward passa a ser cada vez mais "automático" ou “orgânico", ou seja, passa a fazer parte de uma inteligência corporal, mais intuitiva, menos racional.

Quanto ao feedback, expressão já mais conhecida porque utilizada em muitos

${ }^{27}$ Pensamos aqui na afirmação de John Cage a partir das White Paintingss de Robert Rauschenberg de que "Uma tela nunca está vazia." (Cage, 2019, p.99) e sua subsequente reflexão acerca da inexistência do silêncio - enquanto ausência total de sons -, que o levou à icônica obra 4'33". 
contextos, trata-se, temporalmente, a nosso ver, do resquício do passado imediato no presente do performer; é o retorno que se tem após alguma ação. Em uma improvisação, por exemplo, se um performer executa uma ação de caminhar em uma determinada direção, isso acarreta (re)ações por parte dos outros parceiros em jogo, e essas ações retornam ao performer enquanto dados espaciais e cinéticos. O "feedback é a informação e a sensação que alguém recebe como resultado de uma ação" (Bogart e Landau, 2017, p.52). Se pensado em uma situação de apresentação, o feedback diz respeito também às reações da plateia.

Feedforward e feedback são, como explicam as autoras, polos ou energias opostos e complementares da experiência cênica, e é necessário treino para afiálos e calibrá-los. A atentividade - ponto de partida e de chegada do treinamento em Viewpoints - refere-se, portanto, a um presente que, a todo instante, é informado pelo passado imediato, mas também apresenta uma série de possíveis futuros igualmente imediatos. No que se refere a esta abertura de caminhos:

Os Viewpoints aliviam a pressão de ter que inventar tudo por si mesmo, de gerar tudo sozinho, de ser interessante e forçar a criatividade. [...] Os Viewpoints nos ajudam a confiar em deixar algo acontecer no palco, em vez de fazer acontecer. [...] Nos Viewpoints, não há bom ou mau, certo ou errado - há somente possibilidades e, mais tarde no processo, escolhas. [...] Os Viewpoints conduzem a um maior estado de atenção, o qual nos conduz para mais escolhas, que nos conduz para uma maior liberdade (Bogart e Landau, 2017, p.37 - grifo das autoras).

Há um grau de complexidade na prática do Viewpoints perceptível no trecho acima. Certamente, um ator é um agente, alguém que cria, que aposta em um acontecimento, mas um ator não é uma existência abstrata, alheia à realidade cênica, material. Ele existe em um contexto, ele existe com seus parceiros e parceiras, em um determinado espaço e tempo, sempre. A potência do Viewpoints está no processo de compreensão - através da prática - de que a força do ator não está em criar eventos cênicos "do nada", pautados em ideias prévias supostamente geniais, mas sim em perceber o arranjo dos elementos cênicos (espaciais, cinéticos, sonoros) e agir através de escolhas baseadas em fatos, em uma realidade que se apresenta na fugacidade do tempo presente.

Improvisar em Viewpoints é uma busca constante por não racionalizar, não 
premeditar um acontecimento antes que ele efetivamente exista enquanto possibilidade na improvisação. Não forçar, portanto. No entanto, não se trata de nada fazer. Trata-se - e esta é uma linha tênue - de ter a sensibilidade e a escuta extraordinária para perceber os eventos que estão prestes a acontecer e se perceber neles, ou possivelmente fora deles! Não há obrigações em uma improvisação. Há, como já foi dito, regras, possibilidades e escolhas.

No workshop na SITI Company, ao final de uma sessão de open Viewpoints, tentávamos explicar como era incômoda a sensação de que, ao perceber e ler cada vez mais as composições acontecendo - via feedforward -, de certa forma nos sentíamos rendidos, tendo de, a todo instante, responder aos chamados silenciosos dos companheiros de cena. Ingenuidade nossa. A partir da resposta de Will Bond a esse incômodo, assim registramos após o encontro: "Praticar Viewpoints é uma vibração/oscilação constante entre responder aos estímulos e resistir a eles. Às vezes eu posso sentir um impulso, resistir e apenas respirar, vendo um evento acontecer".

É esta a liberdade da improvisação: a escolha. E escolher é lidar com Story. Mesmo em uma improvisação, lidar com os viewpoints é optar a cada momento, é compor com os outros elementos inumanos e humanos com os quais se está compartilhando um espaço-tempo. Por isso, dizemos que praticar o Viewpoints é também praticar o olhar compositor.

A prática não está relacionada a dizer "sim" a tudo que as composições fortuitas dos corpos no espaço the convidam. A importância da prática - neste sentido, próxima à noção de treinamento, aprimoramento - diz respeito ao aumento dos caminhos, das possibilidades. A prática leva a uma expansão da sensibilidade e da atentividade, que, por conseguinte, leva à percepção de um número maior de possibilidades, o que acarreta uma maior liberdade de escolha. "A improvisação aberta com os SSTEMS é uma chance de habitar uma dimensão performativa que é uma mistura igualitária de acaso e escolha” (Overlie, 2016, p.80)28. Quando improvisando coletivamente, o futuro não está apenas em suas mãos, mas está também; e, como disse Overlie (2016, p.51), “[a] arte só pode 
acontecer se você tiver a sensibilidade para percebê-la"29.

Frente a um estímulo, a um impulso: ir ou não ir; agir em consonância com uma ação externa ou agir em oposição a ela, em resistência ou contraste. Certa vez, em um workshop de Viewpoints, o ator norte-americano Thadd McQuade ${ }^{30}$, que estava na condução, explicou que organizava os viewpoints de maneira distinta dos membros da SITI Company, com quem havia aprendido e praticado. Acima ou anteriormente aos viewpoints de tempo e de espaço, ele localizava o viewpoint de repetição e um viewpoint, por ele inventado, de oposição. Ou seja, à parte dos viewpoints enquanto parâmetros ou materiais de criação, ele estabelecia estes dois viewpoints como dinâmica de composição ${ }^{31}$.

Neste raciocínio de jogo do ator norte-americano, frente a um estímulo, ou se o repete - pensando a repetição de maneira expandida, claro, enquanto consonância - ou a ele se se opõe, em dissonância, diferença. Tal modo de pensar e praticar o Viewpoints guarda semelhança com a maneira como Fayga Ostrower (1983) explica a composição em artes visuais, fazendo uso dos termos semelhanças e contrastes, entendidos em uma ampla gama de possíveis graus (maiores, menores) e níveis (as várias relações possíveis de se estabelecer em uma mesma composição). Um elemento estético, seja ele um ponto ou uma linha em uma tela, uma caminhada lenta ou uma forma corporal estática em uma improvisação cênica, por exemplo, nunca será semelhante ou contrastante por si só. O raciocínio compositivo é sempre contextual e relativo: são necessários uma referência e um critério de comparação ${ }^{32}$.

A maneira como cada pessoa lê uma composição espacial é subjetiva, pois há sempre uma gama de possíveis critérios (ou pontos de vista!) a serem

${ }^{29}$ Art can only happen if you have the sensibility to perceive it.

${ }^{30}$ O workshop aconteceu nos dias 1 e 2 de dezembro de 2017 no Teatro da Revista, em São Paulo. McQuade não fez ou faz parte da SITI Company.

${ }^{31}$ Além do par "repetição/oposição", a organização de McQuade dos viewpoints também se diferenciava daquela proposta por Bogart e Landau ao introduzir "orientação" nos viewpoints físicos de espaço, bem como "aceleração/desaceleração" - presentes nos viewpoints vocais de Bogart - nos viewpoints físicos de tempo.

32 Ostrower faz uso desses termos, desse raciocínio, ao pensar a análise via fruição de uma obra. No que concerne à criação da obra, a autora afirma que as opções do artista são intuitivas, guardando, portanto, diferenças com relação ao pensamento que aqui articulamos sobre a prática (criação) do Viewpoints estar entre a intuição e a análise (olhar compositivo), entre o acaso e a escolha. 
considerados. Retomando a afirmação de Overlie, o Viewpoints é uma mistura de acaso e escolha. Para quem está improvisando, acreditamos que vale sempre a tônica: "Com o que eu estou me relacionando, neste momento?" - qual viewpoint, qual elemento externo a mim, qual outro performer, através de qual parâmetro? Ou, dito de outro modo: "Onde está meu interesse?".

A presença cênica no Viewpoints se dá em grande parte a partir da contínua atentividade do performer aos elementos e fatores externos a ele, e não apenas aos internos. Percebemos que é comum iniciantes incomodarem-se e afirmarem que o Viewpoints é uma técnica de improvisação demasiado lógica ou racional o que não está errado nem certo. São, de fato, muitos parâmetros e focos de atenção para se ter em mente continuamente. Acerca disto:

Reconheça esse dilema com o grupo. É natural e inevitável. Você pratica Viewpoints para tornar-se mais consciente. Mas, no começo, você se sentirá autoconsciente. Mais tarde, com prática e perseverança, essa autoconsciência se dissolverá em uma espécie de hiperconsciência um estado constante de atenção intensificada que é conquistado sem esforço ou pensamento (Bogart e Landau, 2017, p.82 - grifo das autoras).

Entre o analítico e o intuitivo, entre o frio e o quente, entre as tarefas e a improvisação, entre a meditação e a composição, entre o exterior e o interior, entre o teatro e a dança, entre o acaso e a escolha: a prática do Viewpoints encontra-se neste umbral das artes performativas. Independentemente de preferências estilísticas, sua prática é um percurso frutífero de sensibilização do(a) performer e de sua relação com parceiros e parceiras, bem como com qualquer espaço físico onde possam as artes performativas acontecer.

\section{Referências}

ALMEIDA, K. C. de; OLINTO, L. A experimentação como território: o legado indisciplinar de John Cage. Urdimento, Revista de Estudos em Artes Cênicas, Florianópolis, v. 1, n. 28, p. 15-34, 2017.

BANES, Sally. Democracy's body: Judson Dance Theater 1962-1964. Durham, London: Duke University Press, 1993. 
BOGART, Anne; LANDAU, Tina. O livro dos viewpoints. Organização e tradução de Sandra Meyer. São Paulo: Perspectiva, 2017.

CAGE, John. Silêncio. Tradução de Beatriz Bastos e Ismar Tirelli Neto. Rio de Janeiro: Cobogó, 2019.

GIL, José. Movimento total: o corpo e a dança. São Paulo: Iluminuras, 2004.

GROTOWSKI, Jerzy. Performer. Tradução de Patricia Furtado de Mendonça. eRevista Performatus, Inhumas, ano 3, n. 14, jul. 2015. Disponível em: https://performatus.com.br/traducoes/performer/. Acesso em: 20 jul. 2021.

MORRIS, Robert. O tempo presente do espaço [1978]. In: FERREIRA, Glória; COTRIM, Cecília (Org.). Escritos de Artistas: anos 60/70. Tradução de Pedro Süssekind et al. Rio de Janeiro: Zahar, 2006, p. 401-420.

OSTROWER, Fayga. Universos da arte. Rio de Janeiro: Campus, 1983.

OVERLIE, Mary. Standing in Space: The Six Viewpoints Theory \& Practice. Billings: Artcraft Printers, 2016.

RAINER, Yvonne. A Quasi Survey of some "Minimalist" Tendencies in the Quantitatively Minimal Dance Activity Midst the Plethora, or an Analysis of Trio A. In: BATTCOCK, Gregory (Org.). Minimal art: a critical anthology. Berkeley, Los Angeles, London: University of California Press, 1995, p.263-273.

RINALDI, Miriam. Teoria e Prática do Viewpoints: Mary Overlie, Anne Bogart e Coletivo Improviso. 2016. Tese (Doutorado em Artes Cênicas). Escola de Comunicações e Artes, Universidade de São Paulo, São Paulo, 2016.

Recebido em: 15/08/2021

Aprovado em: 23/11/2021 